Patricia Roccon Bianchi

Molini ${ }^{1}$

Tânia Regina Grão Velloso ${ }^{2}$

Daniela Nascimento Silva ${ }^{2}$

Rossiene Motta Bertollo ${ }^{2}$ Sergio Lins Vaz de Azevedo ${ }^{2}$ Teresa Cristina Rangel Pereira ${ }^{2}$

Liliana Aparecida Pimenta de Barros ${ }^{2}$

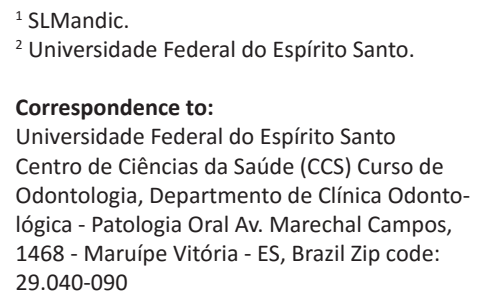

Article received on December 31, 2014. Article accepted on December 15, 2016.

DOI: $10.5935 / 2525-5711.20160020$

\title{
Pigmented lesion in hard palate: a graphite tattoo
}

\begin{abstract}
:
Oral pigmented lesions are commonly noted in odontologic practice. Clinical features of malignant and benign lesions show enough similarity that makes clinical differentiation difficult or impossible. Exogenous pigmentations in orign are usually due to a foreign-body implantation in the oral mucosa and the graphite as an exogenous source of pigmentation in the oral cavity has been reported sporadically. This report is presents a case of a graphite tattoo in hard palate of a young female adult and discusses the diferential diagnosis with blue nevus and early oral melanoma. It reinforces that oral pigmented lesions must be carefully evaluated and a malignant lesion should not be ignored until a final diagnosis be established.
\end{abstract}

Keywords: Diagnosis, Oral; Diagnosis, Differential; Pigmentation; Graphite 
Oral pigmented lesions are commonly noted in clinical practice and features of both malignant and benign lesions show enough similarity being their differentiation a challenge for the professional ${ }^{1}$. The color of these lesions can be attributed to accumulation of pigmented material in abnormal amounts or location in the tissues and may have exogenous or endogenous etiology. Exogenous pigmentations are usually due to a foreign-body implantation in the oral mucosa ${ }^{2,3}$ and may include carbon, iron dust, metallic silver (amalgam tattoos) or graphite. The presence of graphite as an exogenous source of pigmentation in the oral cavity has been reported sporadically ${ }^{4}$. Graphite may be introduced into the oral mucosa through accidental injury with a graphite pencil and appears as an irregular gray to black macule usually in hard palate of young patients ${ }^{3,5-7}$. In addition, graphite tattoos, as well as any pigmented lesion in the oral mucosa, require an extensive differential diagnosis to rule out a possible malignant condition.

\section{CASE REPORT}

A 27 year-old healthy white female patient was referred for evaluation of a focal pigmented lesion in hard palate. Intraoral examination showed an asymptomatic, firm, well-defined blue-black flat macule measuring $0.7 \mathrm{x}$ $0.5 \mathrm{~cm}$ located on the right posterior hard palate (Figure 1). Examination of neck, head and other intraoral structures revealed no abnormalities. The patient had first noticed this lesion about 4 months before and stated not changes in size or color. Intraoral radiography showed no different radiopacity. The clinical differential diagnosis included blue nevus and oral melanoma. An excisional biopsy was performed and after the surgical removal of the lesion, residues of solid black granules attached to the bone were observed (Figure 2). The specimen (Figure 3 ) was fixed in 10\% formalin and sent for histopathological examination.

\section{MACROSCOPY AND MICROSCOPY}

A gray-black single firm and ellipsoidal specimen with irregular surface measuring $1.0 \times 0.5 \times 0.4 \mathrm{~cm}$ was evaluated. A solid black mass with bright spots was observed inside the soft tissue. Microscopic analysis revealed, under the oral mucosa, an intense granular inert and black material mixed between multinuclear giant cells compatible with a foreign-body reaction. There was no evidence of cellular atypia (Figure 4). The solid granules were consistent with graphite.

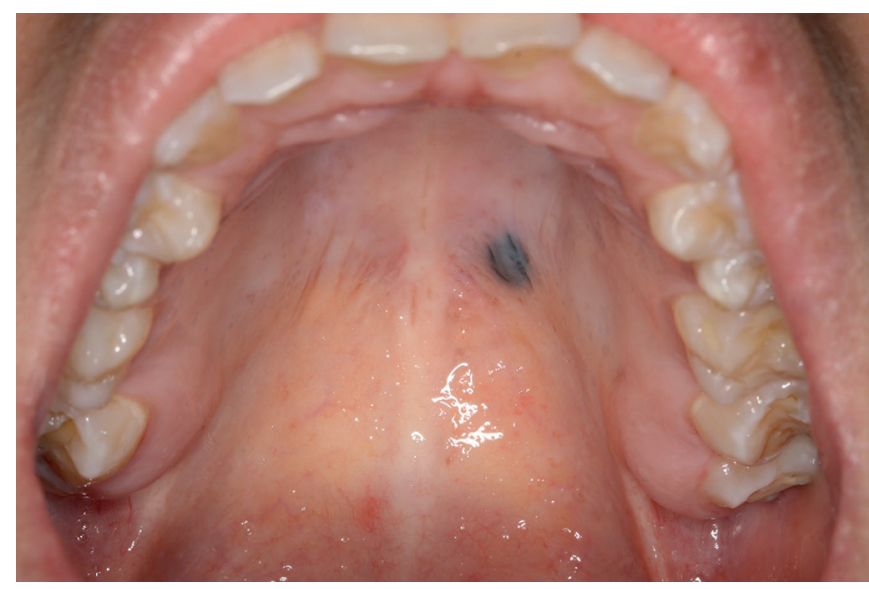

Figure 1. Clinical features: a blue-black macule on posterior hard palate

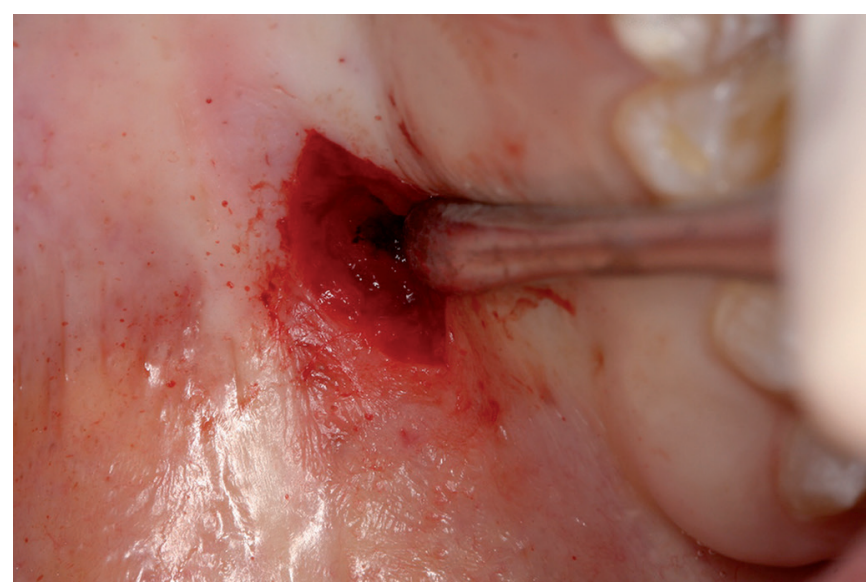

Figure 2. The palate area after surgical removal. Note black granules residues attached to the bone .

\section{DISCUSSION}

Graphite pencils, in addition to their use as teaching tools, may cause traumatic injury and foreignbody reaction, especially during early childhood ${ }^{5}$. Compared to other foreign tattoos, the graphite pigmentation is rarely documented in literature, but they probably occur more often than those indicated by the reported cases $^{6}$. This paper shows a case of a pigmented lesion in hard palate by an implantation of graphite in a young adult and discusses its differential diagnosis due to the location of the lesion and infrequent report.

A history of injury could confirm the diagnosis of a foreign-body lesion ${ }^{3,4,7}$ but as malignant and benign pigmented oral lesions show clinical characteristics that make their differentiation difficult, if not impossible ${ }^{1}$, the biopsy is mandatory to the definitive diagnosis and rule out malignant lesions such as melanoma: This patient did not report injuries in her medical and dental history. 


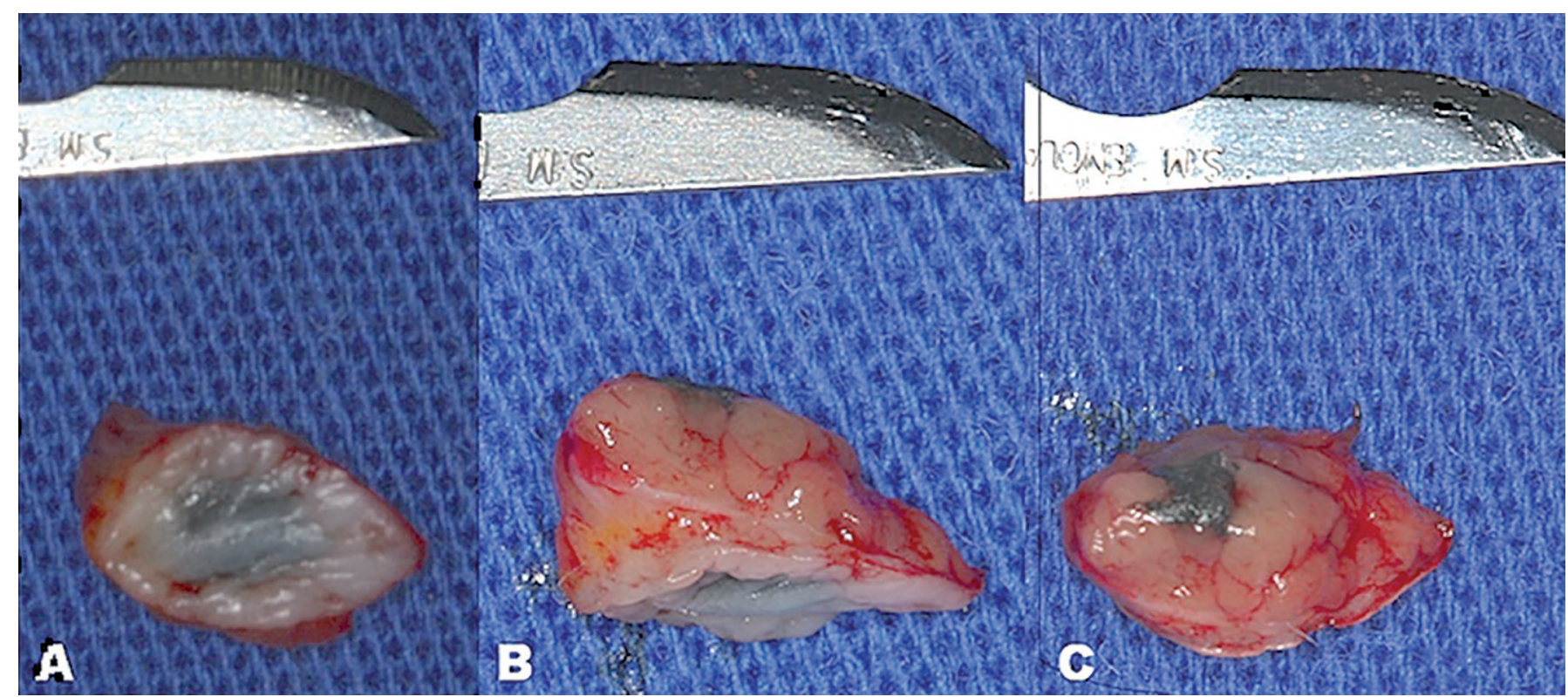

Figure 3. Specimen after surgical procedure. A- front, B-lateral, C- bottom
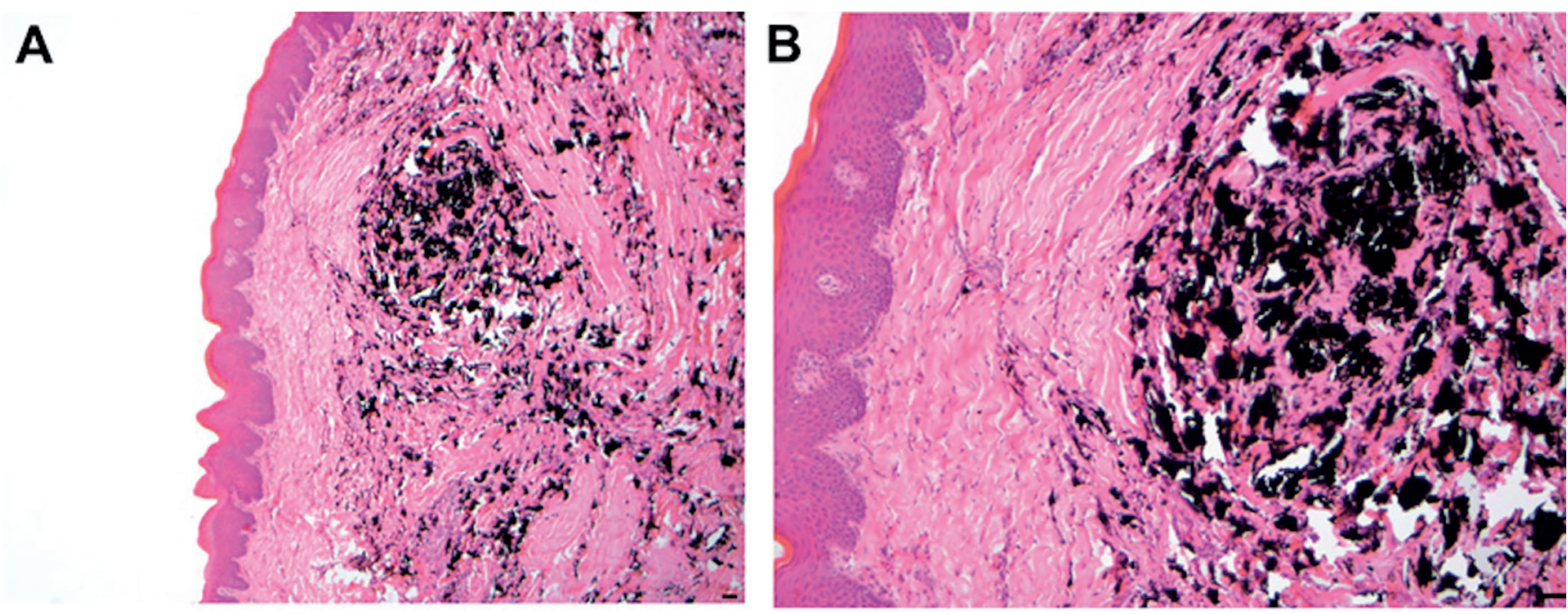

Figure 4. Microscopic views. Solid black granules and multinuclear giant cells compatible with a foreign-body reaction. H.E.: A - 4X; B- 10X.

The diagnostic hypotheses were blue nevus or an early oral melanoma, because of the history, clinical features and location on hard palate. The amalgam tattoo was not considered in differential diagnosis since the patient had no present or past amalgam restorations.

Oral malignant melanoma is a rare and very aggressive tumor of melanocytic origin and represents $0,5-1 \%$ of all oral malignancies ${ }^{3,8-13}$. Because of the lack of early signs and symptoms mucosal melanomas can be mistaken for other diseases and are usually diagnosed in advanced stages ${ }^{12}$. The initial lesion can be a flat asymptomatic macula, slow-growing with irregular borders and strong pigmentation. The most common site is the palate followed by the maxillary gingival ${ }^{8-13,15}$.
The age of patients ranges from 20-80 years ${ }^{11}$. Histologically it is characterized by a proliferation of malignant melanocytes along the junction between the epithelial and connective tissues, as well as within the connective tissue ${ }^{3}$. Most of oral melanoma arises from an apparently normal mucosa, although prior history of pigmentation in the area of the tumor has been reported ${ }^{12,13,16}$. This patient related no symptoms and was unaware of the palatal lesion up to one year before the intraoral examination. Other clinical characteristics such as color and location, could suggest an early malignant melanoma.

On the other hand, blue nevus is a benign acquired melanocitic lesion that usually also presents as an 
asymptomatic, blue-gray or slate-blue smooth-surfaced macule or papule measuring less than $1 \mathrm{~cm}^{3,9}$. Besides rare in oral cavity, the oral blue nevus is the second most common type of oral melanocytic nevi ${ }^{15,19,21}$. It is characterized by a proliferation of dermal melanocytes within the deep connective tissue at some distance from the surface epithelium, which accounts for the blue colour ${ }^{3}$. Intraoral lesions are also frequently in hard palate ${ }^{15,18-21}$ and between the third and fifth decades of life. Females tend to be more commonly affected than males. The risk of malignant transformation of the blue nevus is controversial ${ }^{12,14,15,20,21}$.

Based on clinic characteristics and dental history of this patient it was not possible to differentiate the foreign-body pigmented lesion from a blue nevus or an early lesion of oral melanoma, especially in the palate, a common site for these both lesions. The biopsy excluded a malignant condition and defined the diagnosis, although during the surgical procedure and macroscopic cut evaluation black solid granules were observed in the mucosa and bone at the surgical site as well as in the specimen obtained which suggested a foreign-body lesion. Interestingly, only after the diagnosis information, the patient reported a graphite pencil injury when she was a child. Normal oral mucosa is observed in one-year follow-up (Figure 5).

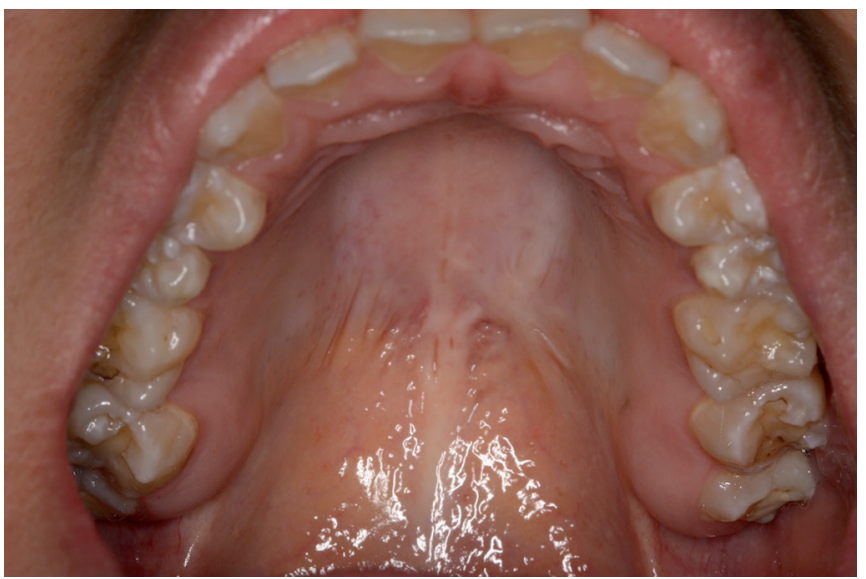

Figure 5. One year follow-up.

This case report would like to reinforce that oral pigmented lesions must be carefully evaluated and a melanoma must not be ignored until a final diagnosis be established.

\section{REFERENCES}

1. Anderegg C R Jr, Lyles M B. Graphite tattoo: report of a case and differential diagnosis. Mil Med 1992; 157: 323-324.

2. De Giorgi V, Sestini S, Bruscino N, Janowska A, Grazzini M, Rossari S, Lotti T. Prevalence and distribution of solitary oral pigmented lesions: a prospective study. J Eur Acad Dermatol Venereol. 2009; 23:1320-1323.

3. Kauzman A, Pavone M, Blanas N, Bradley G. Pigmented lesions of the oral cavity: review, differential diagnosis, and case presentations. J Can Dent Assoc 2004; 70:682-683.

4. Phillips G E, John V. Use of a subepithelial connective tissue graft to treat an area pigmented with graphite. J Periodontol 2005; 76:1572-1575.

5. Rihani F B, Da'ameh D M. Intraoral graphite tattoo. Arch Dis Child 2006; 91:563.

6. Neville B W, Damm D D, Allen C M, Bouquot J E. Oral and Maxillofacial Pathology. 3rd ed. Toronto: W.B Saunders Company; 2009.

7. Moraes RM, Gouvêa Lima Gde M, Guilhermino M, Vieira MS, Carvalho YR, Anbinder AL. Graphite oral tattoo: case report. Dermatol Online J. 2015 Oct 16;21(10).

8. Meleti M, Vescovi P, Mooi WJ, van der Waal I. Pigmented lesions of the oral mucosa and perioral tissues: a flowchart for the diagnosis and some recommendations for the management. Oral Surg Oral Med Oral Pathol Oral Radiol Endod 2008; 105:606-616.

9. Müller S. Melanin-associated pigmented lesions of the oral mucosa: presentation, differential dignosis, and treatment. Dermatol Ther 2010; 23:220-229.

10. Mohan M, Sukhadia VY, Pai D, Bhat S. Oral malignant melanoma: systematic review of literature and report of two cases. Oral Surg Oral Med Oral Pathol Oral Radiol 2013;116:247-254

11. Meleti M, Leemans CR, Mooi WJ, Vescovi P, van der Waal I. Oral malignant melanoma: a review of the literature. Oral Oncol. 2007; 43:116-121.

12. Femiano F, Lanza A, Buonaiuto C, Gombos F, Di Spirito F, Cirillo N. Oral malignant melanoma: a review of the literature. J Oral Pathol Med 2008; 37:383-388.

13. Meleti M, Leemans CR, Mooi WJ, van der Waal I. Oral Malignant Melanoma: The Amsterdam Experience. J Oral Maxillofac Surg 2007; 65:2181-2186.

14. Hatch CL. Pigmented lesions of the oral cavity. Dent Clin North Am 2005; 49:185-201.

15. Buchner A, Merrell PW, Carpenter WM. Relative frequency of solitary melanocytic lesions of the oral mucosa. J Oral Pathol Med 2004; 33:550-557.

16. Kahn MA, Weathers DR, Hoffman JG. Transformation of a benign oral pigmentation to primary oral melanoma. Oral Surg Oral Med Oral Pathol Oral Radiol Endod 2005; 100:454-459.

17. Scully C, Felix DH. Oral medicine--update for the dental practitioner: red and pigmented lesions. Br Dent J 2005; 199:639-645.

18. Santos T de S, Frota R, Martins-Filho P R, Cavalcante J R, Raimundo Rde C, Andrade E S. Extensive intraoral blue nevuscase report. An Bras Dermatol 2011; 86: S61-65. 
19. Lee H Y, Na S Y, Son Y M, Kang H K, Baek J O, Lee J R, Roh J Y. A malignant melanoma associated with a blue nevus of the lip. Ann Dermatol. 2010; 22:119-124.

20. Pinto A, Raghavendra S, Lee R, Derossi S, Alawi F. Epithelioid blue nevus of the oral mucosa: a rare histologic variant. Oral Surg Oral Med Oral Pathol Oral Radiol Endod. 2003; 96:429-436.
21. Meleti M, Mooi W J, Casparie M K, van der Waal I. Melanocytic nevi of the oral mucosa - no evidence of increased risk for oral malignant melanoma: an analysis of 119 cases. Oral Oncol 2007; 43:976-981. 